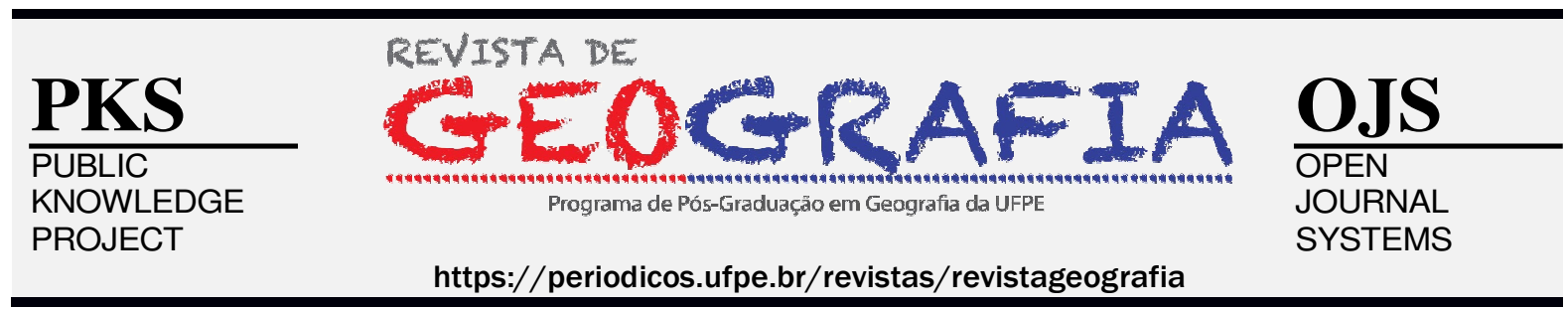

\title{
ASPECTOS SOCIAIS, ECONÔMICOS E AMBIENTAIS DA PESCA DO BIVALVE ANOMALOCARDIA BRASILIANA EM PRAIAS DA REGIÃO DA COSTA BRANCA DO NORDESTE BRASILEIRO
}

\author{
Allyssandra Maria Lima Rodrigues Maia ${ }^{1}$, Eudilena Laurindo de Medeiros², Gustavo \\ Gonzaga Henry-Silva ${ }^{3}$
}

\begin{abstract}
${ }^{1}$ Universidade do Estado do Rio Grande do Norte (UERN). E-mail: allyssandramr@hotmail.com ORCID: http://orcid.org/0000-0001-6590-5095

2 Faculdade Regional da Bahia (UNIRB). E-mail:eudilena@hotmail.com ORCID: http://orcid.org/0000-00026628-7310

3 Universidade Federal Rural do Semi-Árido (UFERSA), Departamento de Biociências. Email:gustavo@ufersa.edu.br ORCID: http://orcid.org/0000-0001-5067-225X
\end{abstract}

Artigo recebido em 03/04/2020 e aceito em 28/02/2021

\begin{abstract}
RESUMO
O objetivo do trabalho foi analisar aspectos sociais, econômicos e ambientais da pesca do bivalve Anomalocardia brasiliana em praias do Rio Grande do Norte por marisqueiras vinculadas a uma associação e por aquelas sem vínculo. A pesca do marisco ocorreu durante todo o ano, com maior produção entre os meses de maio e agosto. O tamanho médio do marisco extraído foi de $24 \mathrm{~mm}$ de comprimento, com comercialização para estabelecimentos comerciais, comerciantes livres e turistas. Entre as marisqueiras associadas foi constatado que $78 \%$ dedicam-se até 15 dias a atividade de extração do marisco, enquanto que $75 \%$ das não-associadas dedicam mais de 15 dias por mês. $89 \%$ das marisqueiras associadas passam mais de $4 \mathrm{~h} / \mathrm{dia}$ na atividade mariscagem, enquanto que as marisqueiras não-associadas permanecem no máximo 4h/dia, sendo que todas as marisqueiras não fazem uso de equipamentos de proteção individuais. Pôde-se concluir que apesar do lucro com a venda do marisco não ser elevado, ele complementa os ganhos com aposentadorias e bolsa família. Apesar das dificuldades, as mulheres consideram que vale a pena continuar com a atividade da pesca do marisco. A organização das marisqueiras em associações é outro aspecto que pode proporcionar melhorias em suas condições socioeconômicas.
\end{abstract}

Palavras chave: pesca artesanal, recurso pesqueiro, semiárido brasileiro, marisco. 


\title{
SOCIAL, ECONOMIC AND ENVIRONMENTAL ASPECTS OF ANOMALOCARDIA BRASILIANA BIVALVE FISHING ON BEACHES IN THE COSTA BRANCA REGION OF NORTHEASTERN BRAZIL
}

\begin{abstract}
The objective of the work was to analyze social, economic and environmental aspects of the fishing of the bivalve Anomalocardia brasiliana on beaches in Rio Grande do Norte by mollusk fisherwomen linked to an association and by those non-members. Shellfish fishing occurred throughout the year, with higher production between May and August. The average size of the extracted seafood was 24.0 $\mathrm{mm}$ in length, with sales to commercial establishments, free traders and tourists. Among the associated mollusk fisherwomen, it was found that $78 \%$ devote up to 15 days to shellfish harvesting activity, while $75 \%$ of non-members devote more than 15 days per month. $89 \%$ of the associated mollusk fisherwomen spend more than $4 \mathrm{~h} /$ day in the shellfish activity, while the non-associated shellfish gatherers stay a maximum of $4 \mathrm{~h} /$ day, and all mollusk fisherwomen do not use individual protective equipment. It is concluded that although the profit from the sale of seafood is not high, it complements the gains with pensions and family allowance. Despite the difficulties, women consider it worthwhile to continue the activity of seafood fishing. The organization of mollusk fisherwomen in associations is another aspect that can provide improvements in their socio-economic conditions.
\end{abstract}

Keywords: artisanal fishing, fishery resources, brazilian semiarid, shellfish.

\section{INTRODUÇÃO}

A pesca artesanal é definida como uma atividade familiar de subsistência ou comercial, que utiliza uma quantidade reduzida de capital e energia e que pode fazer uso de pequenas embarcações (FAO, 2014). De acordo com a FAO (2015) mais de $90 \%$ dos pescadores do mundo são artesanais, sendo que a grande maioria atua em países em desenvolvimento. De toda esta força de trabalho, $50 \%$ é constituída por mulheres e $95 \%$ do que é pescado costuma ser destinado para o consumo local. Nesse universo, destacam-se as marisqueiras, principais representantes da pesca artesanal nos estuários, responsáveis pela coleta de marisco, ostra, siri, macroalgas e outros organismos aquáticos. No entanto, apesar da expressividade do setor, estas pescadoras ainda enfrentam condições precárias de trabalho e de empoderamento (HENRY-SILVA et al., 2014a; MATTOS et al, 2017).

É importante mencionar, que há um interesse crescente na relação entre a exploração dos estoques e o comportamento do pescador, sobretudo quanto à percepção ambiental (GUEST, 2003; MONTELES, et al. 2009; MACNAUGHTON et al., 2014). Neste contexto, é necessário o entendimento de quem são os usuários, como utilizam os recursos pesqueiros em 
escalas temporais e espaciais e quais fatores interferem na tomada de decisão sobre o uso destes recursos (ROCHA, 2013). Outro aspecto importante refere-se da relação das marisqueiras com o ambiente natural, seu conhecimento acerca do comportamento, biologia e utilização dos recursos naturais da região onde vivem (BEGOSSI et al., 2006; HENRYSILVA et al, 2014b).

Os moluscos bivalves estão entre os organismos que mais se destacam na pesca extrativista realizada pelas comunidades litorâneas, especialmente por serem facilmente coletados e por não necessitarem de instrumentos elaborados para a sua extração (DIAS, et al. 2007; RIOS, 2009). Na costa brasileira, a pesca do bivalve Anomalocardia brasiliana e de outras espécies de moluscos tem grande importância para pescadores artesanais e suas famílias (OLIVEIRA, et al., 2014; MEDEIROS et al., 2018). Estudos mencionam a importância socioeconômica desta atividade pesqueira para as populações humanas que vivem no litoral de vários estados brasileiros como na Bahia (SOUTO E MARTINS 2009; ANDRADE E SCHIAVETTI, 2015), na Paraíba (NISHIDA, et al. 2004, 2006a, 2008; SANTOS et al., 2017; GOMES et al., 2019; MOURÃO et al., 2020), no Ceará (ARAÚJO e ROCHA-BARREIRA, 2004, ROCHA-BARREIRA e ARAÚJO, 2005) e no Rio Grande do Norte (DIAS et al., 2007; RODRIGUES, et al. 2013).

Apesar da abundância do bivalve A. brasiliana ao longo da costa do Brasil, a exploração contínua associada à falta de regulamentação e a degradação ambiental litorânea crescente têm sido apontadas como fatores que podem comprometer seus estoques (NISHIDA, et al. 2004, ROCHA, 2013). Outros desafios para a gestão da pesca artesanal, principalmente o extrativismo pesqueiro em regiões estuarinas, é fazer chegar as políticas públicas a estes pescadores, tendo por base a gestão participativa, além de proporcionar acesso mais fácil aos recursos marinhos e aos mercados consumidores (MATTOS, 2014; ROCHA e PINKERTON, 2015; FAO, 2018; GELCICH, 2019). Neste contexto, o presente estudo teve como objetivos caracterizar a pesca artesanal realizada em praias da região da Costa Branca do Rio Grande do Norte, no que se refere aos seus aspectos sociais, econômicos e ambientais. 


\section{MATERIAL E MÉTODOS}

A região da Costa Branca está localizada no litoral setentrional do Rio Grande do Norte, no semiárido nordestino, sendo também conhecida como "Mar do Sertão". Esta região possui uma diversidade de ecossistemas costeiros, tais como manguezais, praias, recifes de corais, campos de dunas, lagoas costeiras e interdunares e regiões estuarinas que proporcionam habitats para uma grande diversidade de organismos (HENRY-SILVA, et al, 2017). O presente estudo foi realizado com as marisqueiras que moram nas comunidades de Barra e Pernambuquinho (Grossos-RN), localizadas próximas a região estuarina do rio ApodiMossoró (0458'47"S; 379'17"W) (Figura 01).

Figura 01. Local do estudo na região da Costa Branca nordestina. Detalhe das praias de Barra e Pernambuquinho próximas a região estuarina do rio Apodi-Mossoró, localizada entre os municípios de Areia Branca e Grossos RN (04 $58^{\prime} 47^{\prime \prime}$; 3 3709'17’'W).

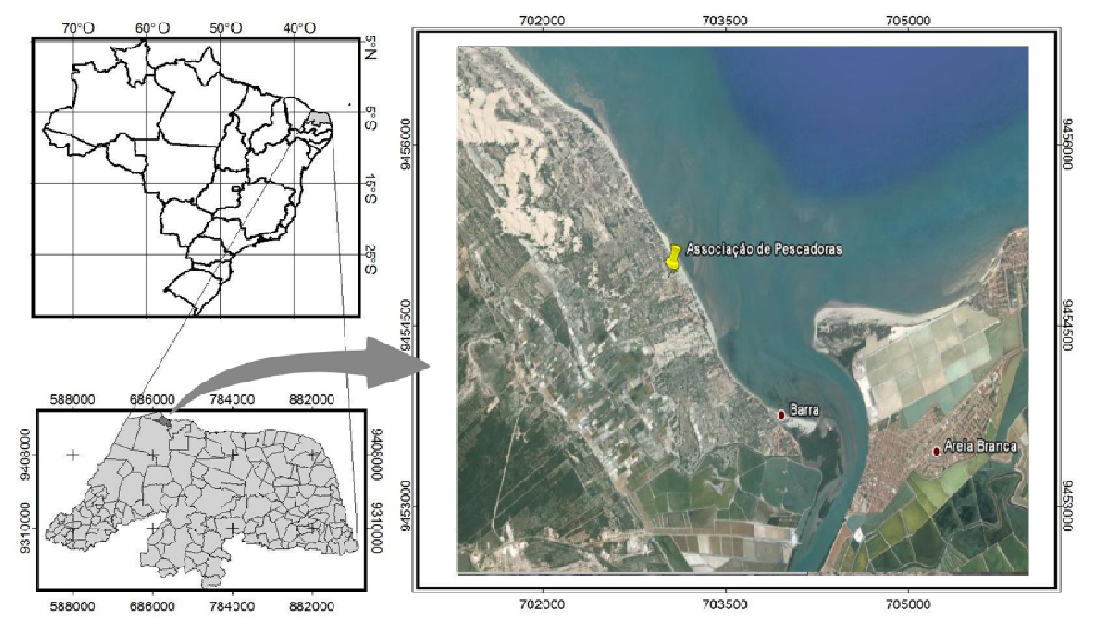

Todas as nove marisqueiras vinculadas a "Associação das Mulheres Pescadoras e Artesãs do Município de Grossos”, (AMPAMG), que é uma entidade civil de direito privado sem fins lucrativos, foram selecionadas para responderem o questionário. Oito marisqueiras não-associadas foram selecionadas por meio de contato informal durante a pesca do marisco nas praias de Barra e Pernambuquinho. Não foi estabelecido como pré-requisito selecionar mulheres que dependiam exclusivamente da renda da comercialização do marisco, no entanto, não foram escolhidas aquelas que realizavam a pesca de $A$. brasiliana apenas para própria 
alimentação e da família. A aplicação do questionário às nove marisqueiras associadas ocorreu individualmente na sede da AMPAMG, enquanto que as marisqueiras não-associadas responderam ao questionário em suas residências.

As informações foram coletadas em maio de 2012, com o auxílio de questionário semiestruturado com perguntas relacionadas aos aspectos sociais, econômicos e ambientais que visaram fazer uma descrição sobre a faixa etária das marisqueiras, tempo de atuação na pesca, unidade de captura, unidade de esforço, restrições encontradas, segurança no trabalho, melhor período de pesca do marisco, escolaridade, informações socioeconômicas (escolaridade, lucro e renda da venda do marisco), o tamanho o qual vem sendo coletado e ainda a percepção das mesmas sobre a recomposição dos bancos de marisco (croas). Também foram obtidos dados da pesca de A. brasiliana pelas marisqueiras no período de abril de 2009 a abril 2012. Estes dados foram obtidos desde 2009 por meio do projeto "Gente da Maré", que foi elaborado pelo Ministério da Pesca e Aquicultura e executados pela Organização Não Governamental World Fisheries Trust, do Canadá, com apoio da FAO e de várias instituições de pesquisa e extensão brasileiras.

\section{RESULTADOS}

No presente estudo, as marisqueiras apresentaram idade entre 18 e 69 anos, sendo que $44,4 \%$ das associadas e $56 \%$ das não associadas estão na faixa etária de 30 a 45 anos. $75 \%$ das marisqueiras não-associadas atuam a mais de 30 anos na mariscagem. Entre as marisqueiras associadas, 34\% possuem o nível médio como maior grau de instrução. Entre as não-associadas, $50 \%$ possuem o nível fundamental e apenas 12,5\% possuem o nível médio.

O principal apetrecho utilizado pelas marisqueiras foi o balde. De uma maneira geral, cada balde contabilizou aproximadamente $16 \mathrm{~kg}$ de $A$. brasiliana, contando com a concha. Depois do processamento do marisco, sobrava em média $1 \mathrm{~kg}$ de carne. Cada marisqueira associada retirava de 1 a 4 baldes por dia de marisco das praias de Barra e Pernambuquinho, ou seja, 1 a $4 \mathrm{~kg}$ de marisco sem concha. Já entre as não-associadas, a produção foi de no máximo 2 baldes por dia (2kg de marisco sem concha/dia/marisqueira) (Figura 02). 
Figura 02. Frequência (\%) da quantidade de captura/dia pelas marisqueiras. Cada balde equivale a $16 \mathrm{~kg}$, depois da retirada da concha, limpeza e processamento do marisco A, brasiliana, gera $1 \mathrm{~kg}$ de carne.

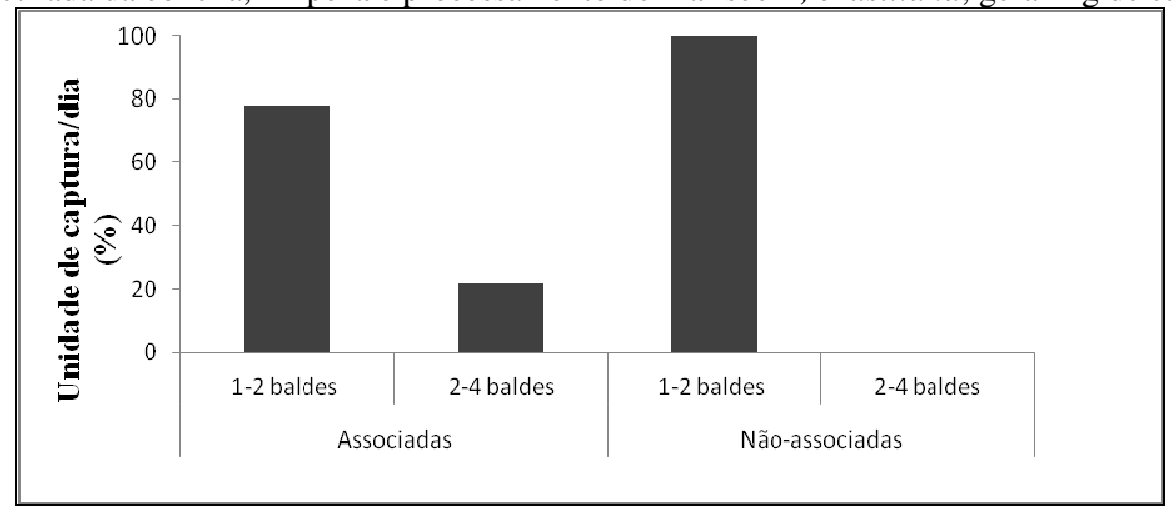

Constou-se que $89 \%$ das marisqueiras associadas permaneciam mais de $4 \mathrm{~h} / \mathrm{dia}$ na pesca do marisco, enquanto que $11 \%$ permaneciam até $4 \mathrm{~h} /$ dia. Entre as marisqueiras nãoassociadas, observou-se que todas permaneciam no máximo até $4 \mathrm{~h} / \mathrm{dia}$ na atividade de mariscagem (Figura 03). Entre as associadas foi constatado que $78 \%$ dedicavam até 15 dias por mês a atividade de extração do marisco, enquanto que apenas $22 \%$ atuavam mais de 15 dias por mês. Vale ressaltar que, enquanto umas realizavam a coleta, outras permaneciam no galpão para limpeza e processamento do marisco. Já para as não-associadas a maioria (75\%) dedicava mais de 15 dias por mês a extração do marisco. O levantamento da pesca feito entre os meses de abril/09 a abril/12, constatou que a produção mensal de marisco obtida pelas oito marisqueiras associadas variou de 130 a $160 \mathrm{~kg}$ (parte mole), sendo que o comprimento médio do marisco foi de 24,0 $\mathrm{mm}$, com tamanhos variando entre 21 e $26 \mathrm{~mm}$ de comprimento.

Entre os fatores que limitaram a atividade de pesca do marisco está a maré alta, presença de chuvas ou ainda motivos relacionados a doenças. A maioria das não-associadas $(62,5 \%)$ afirmaram que não realizavam a atividade se estivesse chovendo. A maioria das marisqueiras vinculadas a associação (56\%) destacaram como maior dificuldade a maré alta de sizígia (Figura 04). 
Figura 03. Frequência (\%) da unidade de esforço (h/dia) da pesca de A. brasiliana.

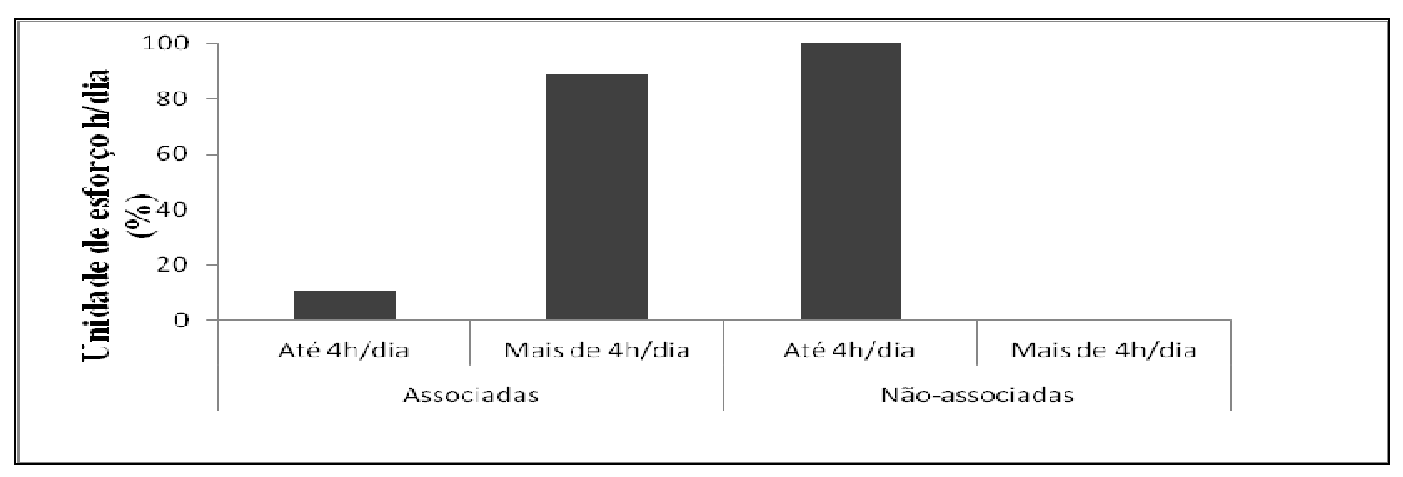

Figura 04. Frequência (\%) de fatores que restringem à atividade de mariscagem.

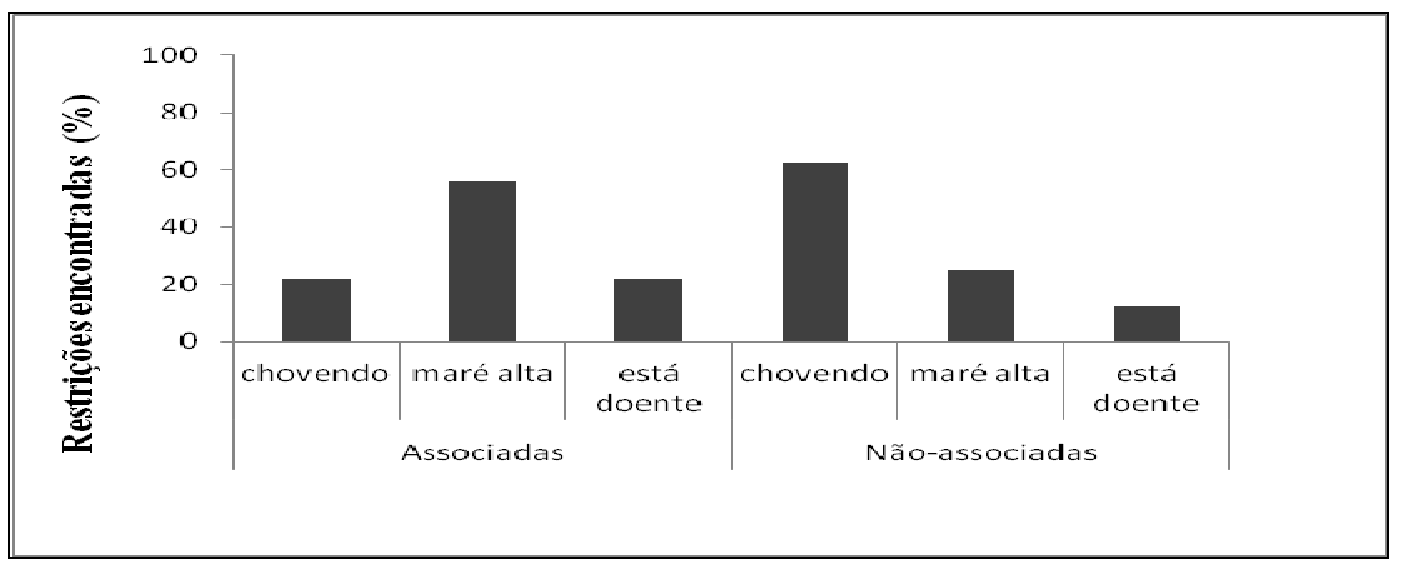

A extração dos mariscos ocorreu sem o uso de equipamentos de proteção individuais, visto que todas as marisqueiras entrevistadas afirmaram não fazer uso de nenhum tipo de equipamento. Entre as marisqueiras não-associadas, verificou-se que 12,5\% delas já se envolveram com acidentes do trabalho durante a mariscagem. O período de maio a agosto foi citado como o melhor para a pesca, devido a maior quantidade de marisco. No restante dos meses do ano, a pesca não correspondeu ao esperado, segundo respostas da maioria das marisqueiras. Todas as marisqueiras associadas elegeram a praia de Barra como melhor local para pesca. Já nas não-associadas 87,5\% mencionaram que o melhor local é a praia de Barra e apenas $12,5 \%$ afirmaram ser a praia de Pernambuquinho. $66,4 \%$ das marisqueiras associadas afirmaram que consomem o marisco a cada dois dias na semana e 33,6\% afirmaram que 
consomem diariamente. Enquanto as não-associadas, 25\% consomem de 3 a 4 dias e $75 \%$ consomem diariamente.

Entre as associadas, $87 \%$ afirmaram que a renda mensal da venda do marisco é de $\mathrm{R} \$$ 200 a 250,00 por pessoa. Já nas respostas das não-associadas a renda chega a ser menor, com $50 \%$ afirmando que a arrecadação é de $\mathrm{R} \$ 200$ a 250,00 e $50 \%$ afirmando que é menor de $\mathrm{R} \$$ 200,00 (Figura 05). Entre as associadas, 66\% afirmaram que estão vinculadas ao Programa Social Federal Bolsa Família, além disso, $12 \%$ são aposentadas e 22\% tem criação de animais. Entre as não-associadas, verificou-se que $87,5 \%$ recebem auxílio do bolsa família e apenas $12,5 \%$ tem criação de animais. Não foi verificada renda de aposentadoria entre as nãoassociadas. Todas as marisqueiras associadas vendem o pescado a estabelecimentos comerciais e atravessadores. Já entre as não-associadas, $75 \%$ vendem a estabelecimentos comerciais e $25 \%$ comercializam a turistas.

Figura 05. Renda das marisqueiras associadas e não-associadas com a pesca do marisco A. brasiliana.

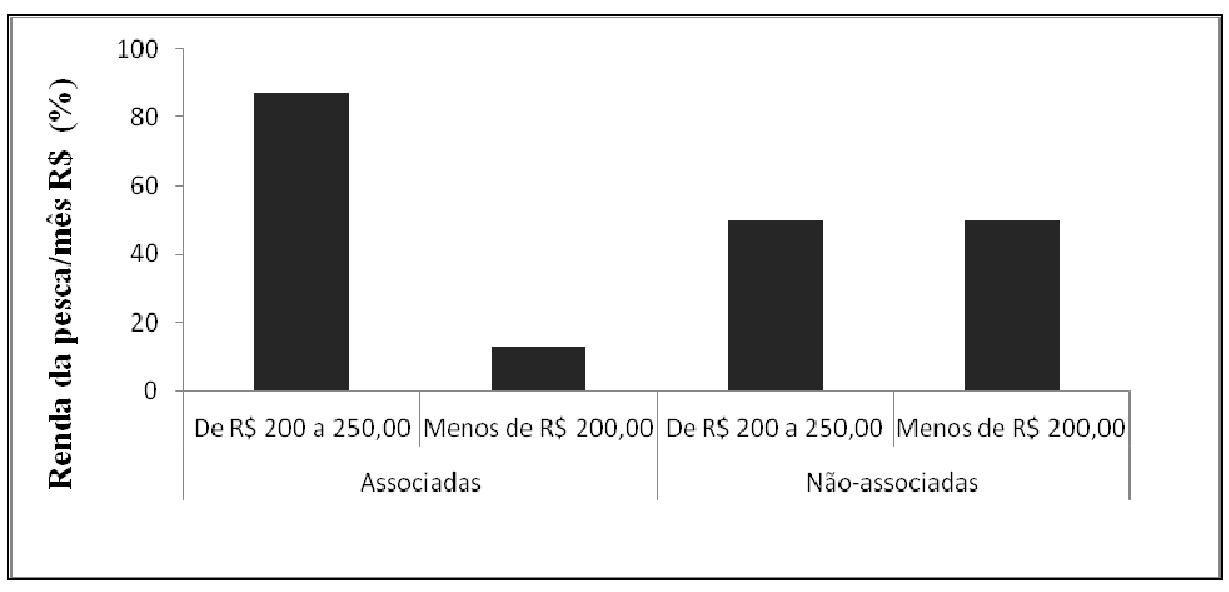

Foi perguntado as marisqueiras se um banco de marisco, que já estivesse reduzido devido a pesca, fosse completamente fechado, em quanto tempo este banco estaria recuperado para que a pesca voltasse a ocorrer novamente. Dentre as associadas, 66,4\% responderam que o tempo necessário seria de 1 a 2 meses. As demais associadas $(33,6 \%)$ afirmaram que entre 2 a 4 meses. Entre as não-associadas, 75\% responderam que seria de 1 a 2 meses de tempo, e apenas $25 \%$ do total afirmaram que seria entre 2 a 4 meses (Figura 06). Entre as marisqueiras 
associadas, todas (100\%) afirmaram que a quantidade de marisco na região tem aumentado. Entre as não-associadas, 62,5\% responderam que tem aumentado (Figura 07).

Figura 06. Percepção sobre a recuperação do banco de A. brasiliana.

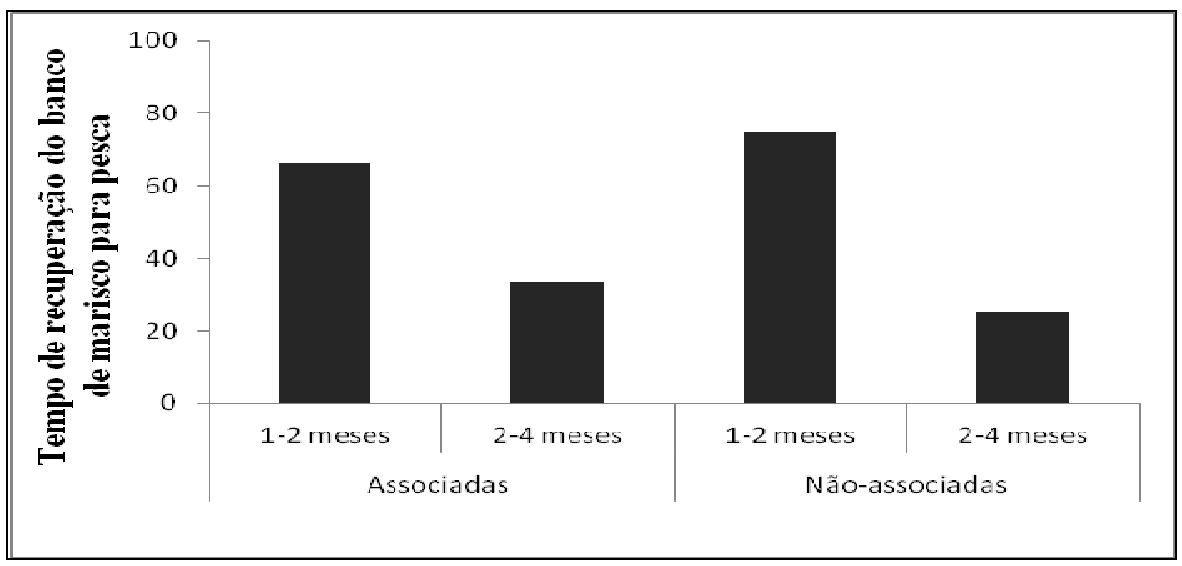

Figura 07. Percepção sobre a quantidade de A. brasiliana nas praias de Barra e Pernambuquinho - RN.

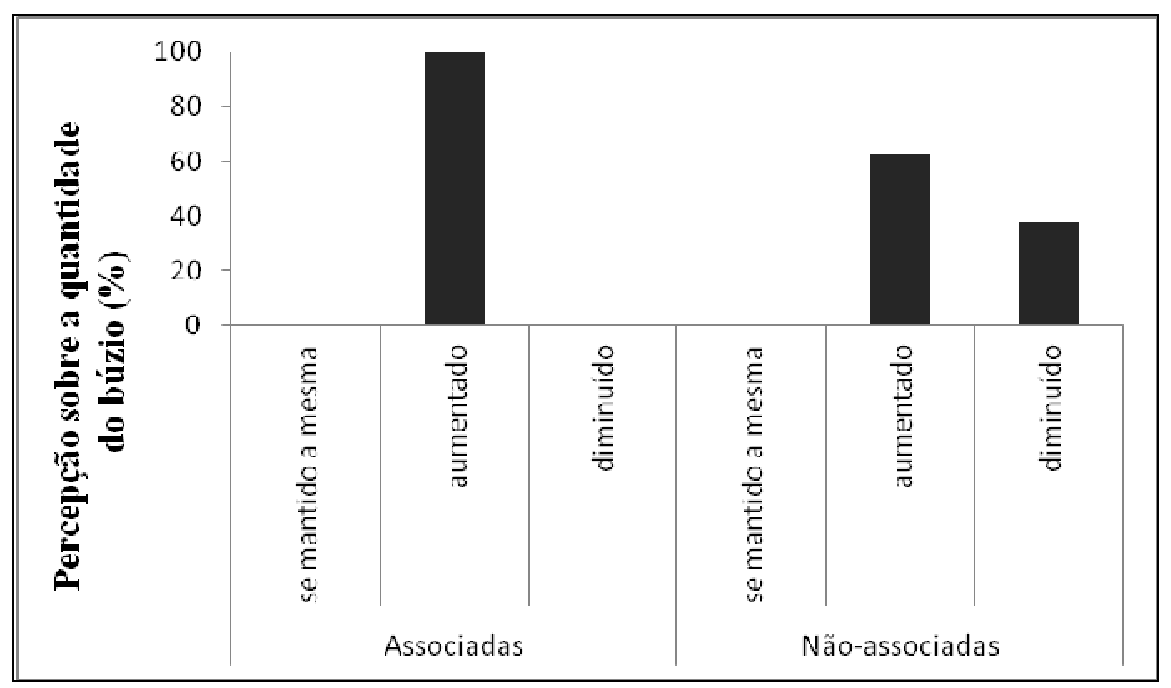

Em relação a visão das pescadoras acerca dos bancos de marisco (croas) explorados, todas as marisqueiras associadas afirmaram que os bancos podem suportar mais pessoas, nenhuma respondeu que já chegou ao limite ou que tem gente demais pescando. Enquanto $65 \%$ das não-associadas afirmaram que podem suportar mais pessoas pescando, 12,5\% responderam que já chegou ao limite e $25 \%$ afirmaram que tem pessoas demais pescando 
nessa área (Figura 08). Dentre as respostas obtidas acerca da visão das marisqueiras sobre a pesca na região, $77 \%$ das associadas responderam que a pesca era boa/alta (antes de 2009), $11 \%$ que era reduzida/razoável (entre 2009/2011) e 12\% que era reduzida (em 2012). Entre as não-associadas, 37,5\% afirmaram que antes de 2009 a pesca era boa/alta, 50\% delas afirmaram que a pesca entre 2009 e 2011 era reduzida/razoável, e 12\% também consideraram a pesca reduzida em 2012 (Figura 09).

Figura 08. Visão dos bancos de A. brasiliana nas praias de Barra e Pernambuquinho - RN.

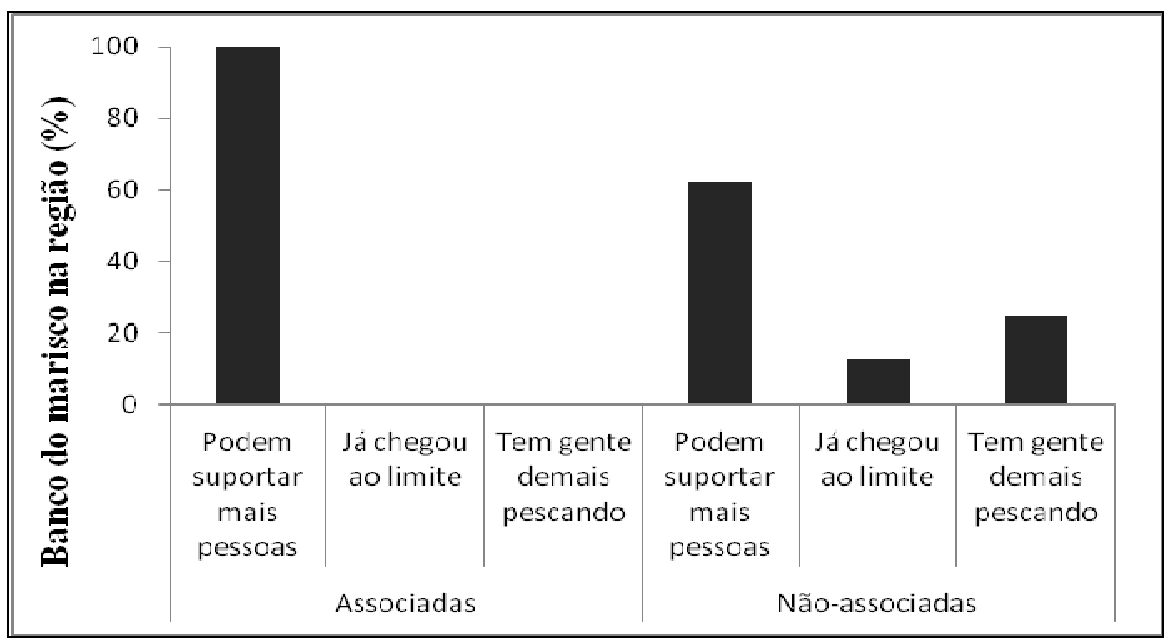

Figura 09. Visão da pesca de A. brasiliana nas praias de Barra e Pernambuquinho - RN.

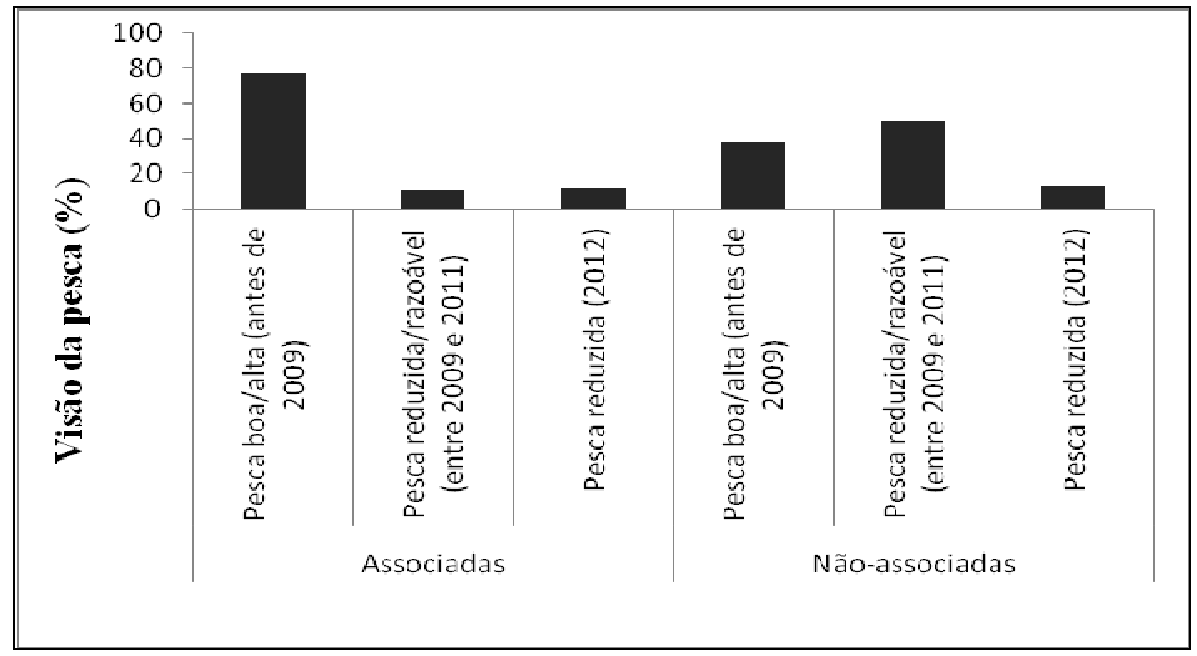




\section{DISCUSSÃO}

Os resultados demonstram que a maioria das marisqueiras atua há mais de 30 anos na pesca do marisco. Begossi et al. (2009), em estudo com pescadores artesanais da Baía da Ilha Grande, verificaram que a idade média dos 21 pescadores entrevistados é de 40 anos, sendo 27 dedicados à pesca e 22 dedicados à pesca no local. Chiba et al. (2012) também verificaram que a pesca artesanal é realizada principalmente por pessoas mais idosas e que exercem essa atividade há mais de 30 anos. Ainda há outro grupo que auxilia na atividade de mariscagem no Brasil, a das crianças, filhos ou ligados por algum laço familiar as pescadoras artesanais. As crianças, quando vão à maré, exercem papel diferenciado, seja ajudando no transporte de apetrechos, na extração propriamente dita ou no acondicionamento das conchas (ROCHA, 2013). Segundo a autora, a intensidade da participação infantil na mariscagem, de uma maneira geral irá depender da idade, da inexistência de atividade escolar no dia e do número de crianças no grupo. No presente estudo, no entanto, não foi verificado a presença de crianças trabalhando com essa atividade de pesca ou ajudando as mães na mariscagem, tanto entre as associadas como no grupo das não-associadas.

No presente estudo, houve uma preferência de pesca do marisco com baldes, tanto para armazenar e transportar quanto para auxiliar na sua extração. Este método de coleta, utilizado pelas marisqueiras que atuam nas praias de Barra e Pernambuquinho do município de Grossos-RN, é denominado localmente como "aguada". Consiste basicamente em utilizar um balde para raspar o sedimento em que se encontra indivíduos de A. brasiliana (Figura 10a), deixando estes bivalves expostos para que em seguida sejam coletados e acondicionados em outro balde maior (Figura 10b). As marisqueiras vinculadas a Associação, após o acondicionamento nos baldes, transferem os mariscos para caixas plásticas vazadas (monoblocos), no intuito de tentarem coletar apenas indivíduos acima de $20 \mathrm{~mm}$ (Figura 10c). 
Figura 10. Marisqueiras realizando a pesca do bivalve A. brasiliana nas praias de Barra e Pernambuquinho, Grossos - RN.
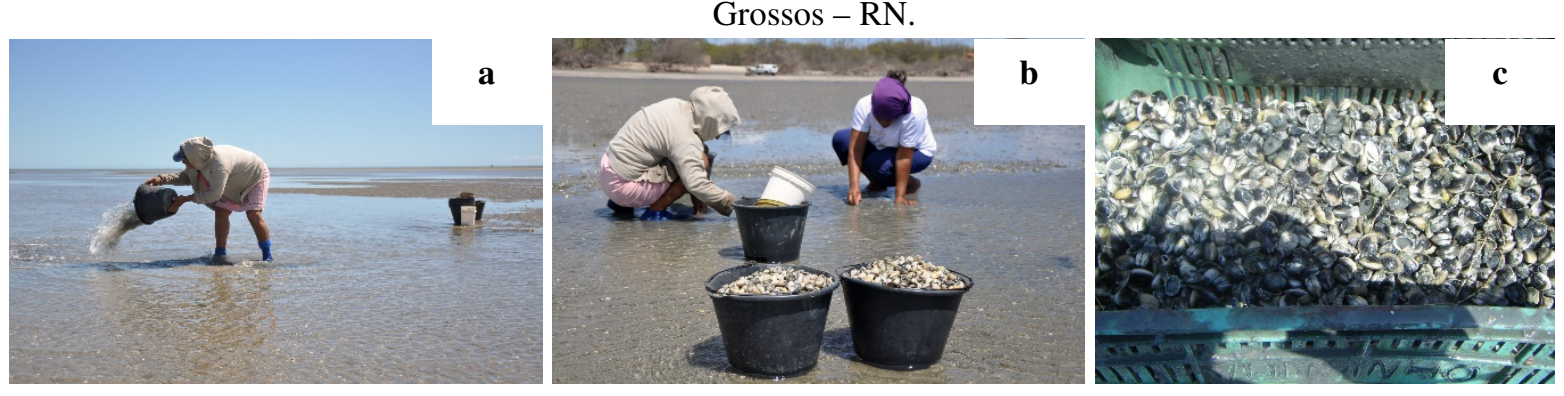

A maior parte das marisqueiras associadas passa mais de 4h/dia dedicada a extração do marisco. Já as marisqueiras não-associadas permanecem na pesca de A. brasiliana no máximo até $4 \mathrm{~h} /$ dia. As mesmas alegaram que devido aos afazeres domésticos não poderiam ficar mais tempo na atividade da mariscagem, além disso, as não-associadas fazem tanto o trabalho de pesca quanto o de limpeza do marisco. Provavelmente estes são fatores importantes que impedem que as mesmas não atuem mais de $4 \mathrm{~h} /$ dia na pesca do marisco se comparadas com as associadas. A quantidade de "idas à maré" com horas dedicadas à cata do marisco pode variar entre as associadas e não-associadas. A periodicidade de vezes na semana que as mulheres "vão à maré" pode variar, dependendo diretamente do número de dias com maré favorável, da necessidade de cada família, da existência de encomendas do produto, do acesso à embarcação (no caso delas não conseguirem ir a pé aos bancos de molusco) e da ausência de doença ou obrigações familiares que as impeçam de trabalhar (MOREIRA, 2007; ROCHA, 2009; ROCHA, 2013). No presente estudo, foi verificado que as marisqueiras associadas possuem um tempo diário maior de dedicação a esta atividade, possuindo encomendas do pescado através de comprador fixo (estabelecimentos comerciais e atravessadores). Entre as não-associadas, a venda ocorre em estabelecimentos e atravessadores, mas também entre os turistas, que ocasionalmente vão à localidade.

Percebe-se que para com as marisqueiras associadas que há um aumento na quantidade da pesca, quando comparada com a pesca feita pelas marisqueiras não-associadas. O fato destas mulheres estarem vinculadas a associação, os critérios de organização, divisão de tarefas com horário e os dias programados para pesca do marisco provavelmente favorecem o aumento da produção. As maiores restrições a pesca mencionadas pelas 
marisqueiras de Grossos foram a maré alta, a chuva e problemas de saúde. Assim como constatado por Dias et al (2007), que acompanharam a extração de marisco na Reserva de Desenvolvimento Sustentável Ponta do Tubarão-RN, a mariscagem nas praias de Barra e Pernambuquinho ocorre nas marés de sizígia, quando durante as luas nova e cheia, as forças gravitacionais do Sol estão na mesma direção das da Lua, produzindo maiores amplitudes de marés. A extração de A. brasiliana pelas marisqueiras associadas e não associadas acontece no período entre a vazante e a enchente das marés sizígia, ou seja, durante cerca de 15 dias por mês.

Apesar de ser considerada uma atividade sazonal, tanto as marisqueiras associadas quanto as não-associadas, afirmaram que o período de maio a agosto é a melhor época para a pesca de moluscos. A mariscagem é uma atividade que acontece ao longo do ano, diminuindo a frequência por algumas razões como dificuldade de produção e beneficiamento, a qualidade da carne hipersalina sensível à diminuição de salinidade e a diminuição do turismo no período chuvoso na região nordeste, que reduz a demanda pelo consumo dos mariscos (NISHIDA et al., 2004; ROCHA, 2013). No presente estudo, apesar do período de veraneio, que vai de janeiro a fevereiro, apresentar uma maior demanda de mariscos, a melhor época considerada pelas marisqueiras para a coleta é de maio a agosto, onde a pluviosidade é menor e o acesso aos bancos de A. brasiliana ocorre mais facilmente. Com base nos dados de produção mensal da pesca $A$. brasiliana realizada pelas marisqueiras associadas, de fato foi constatado que a maior captura deste marisco ocorreu nos meses de maio a agosto.

Os resultados demonstraram que todas as marisqueiras associadas preferem a praia de Barra para a pesca de A. brasiliana. Entre as não-associadas a maioria também prefere a praia de Barra, porém consideram que na praia de Pernambuquinho a pesca também é "muito boa". Vale salientar que, a praia de Barra localiza-se na região estuarina do Rio ApodiMossoró, enquanto que a praia de Pernambuquinho está mais distante, localizada a alguns quilômetros do estuário. Dias et al. (2007), ao avaliarem os aspectos socioeconômicos, percepção ambiental e perspectivas das mulheres marisqueiras no estuário da Reserva de Desenvolvimento Sustentável Ponta do Tubarão - RN, verificaram que a mariscagem praticada nesse estuário representa importante fonte de subsistência e segurança alimentar 
para as comunidades litorâneas, especialmente através da exploração de A. brasiliana. Isso nos permite supor que as áreas estuarinas são locais de preferência para a pesca desta espécie de molusco bivalve.

Definir tamanhos mínimos de coleta é importante para que os indivíduos explorados sejam exclusivamente adultos, ou seja, que já tenho passado ao menos por um ciclo reprodutivo, de maneira a assegurar a manutenção dos estoques. No Brasil há pouco ou nenhum controle em relação ao tamanho dos animais coletados e que o tamanho mínimo da mariscagem está condicionado ao conhecimento das comunidades tradicionais e as necessidades sociais (NISHIDA et al, 2006). No presente estudo, durante o período de 37 meses em que foi acompanhada a produção da pesca das marisqueiras associadas, o tamanho do marisco ficou entre 21 a $26 \mathrm{~mm}$ de comprimento. Foi contatado que as marisqueiras associadas tendem a devolver ao ambiente indivíduos menores que $20 \mathrm{~mm}$. Este comportamento pode estar associado à venda do marisco com comprimentos maiores, gerando mais lucro devido a maior quantidade de carne, demonstrando um pensamento de cunho econômico, mas também a uma medida conservativa de proteção dos estoques naturais, pois indivíduos de A. brasiliana com comprimentos maiores que $20 \mathrm{~mm}$ são considerados adultos e consequentemente já atingiram a sua maturidade sexual (HENRY-SILVA et al., 2014b). Souto e Martins (2009), afirmaram que população tradicional de Acupe (Bahia) também coleta mariscos maiores que $20 \mathrm{~mm}$.

Detectou-se que o consumo do marisco entre as marisqueiras associadas ocorre a cada dois dias na semana ou diariamente. Enquanto entre as não-associadas, a maioria delas consome diariamente. Neste contexto, Ramires et al. (2012), em estudos com os pescadores artesanais de Ilhabela (SP), destacaram que a pesca artesanal é a principal fonte de proteína para as famílias destes pescadores. Percebe-se assim, que além da comercialização do marisco, há também o seu consumo pelas famílias das marisqueiras das comunidades de Barra e Pernambuquinho, sendo uma fonte de proteína importante para estas pessoas.

Os resultados sobre a percepção sobre a conservação e o funcionamento os bancos (croas) de mariscos das praias de Barra e Pernambuquinho, revelaram que a maioria das marisqueiras associadas e não associadas considera que estes bancos podem suportar mais 
pescadoras. Freitas et al. (2012), em estudos com marisqueiras no delta do Rio Parnaíba, destacaram que quando as marisqueiras eram questionadas se sabiam o que era conservação, a maioria respondia que não, enquanto o restante associava a conservação do meio onde vivem como forma de proteção para os organismos, através do combate ao desmatamento e a poluição doméstica, garantindo assim, o turismo da região e o sustento das famílias. Huitric (2005), destaca que existe exemplos na América Latina e Espanha, onde a pesca bentônica já sofreu um sério impacto, sendo que o conhecimento sobre a pesca deve vir para dar suporte às estratégias de manejo. Nesse contexto, usar o conhecimento local permite ainda legitimar ações de co-manejo na pesca, que devem necessariamente envolver o sistema de regras e instituições locais (BEGOSSI; 2006, HENS E BEGOSSI, 2008).

No presente estudo, as marisqueiras associadas e não associadas consideraram a pesca de A. brasiliana "boa/alta" até antes de 2009. Já entre os anos de 2009 a 2011 a pesca foi considerada "reduzida/razoável". Rodrigues et al. (2013), avaliando a estrutura populacional de A. brasiliana nas praias de Barra e Pernambuquinho, constataram que durante os meses de abril e maio de 2008, a precipitação pluviométrica foi elevada em toda a bacia hidrográfica do rio Apodi-Mossoró, ocasionando uma drástica diminuição da salinidade da água e um grande aporte de material particulado na região estuarina, que encobriu os bancos de A. brasiliana, tornando o ambiente anóxico. Estas mudanças ambientais causadas pelas chuvas, reduziram a densidade deste bivalve nas praias estudadas a partir do segundo semestre de 2008 e provavelmente nos três anos seguintes, prejudicando a atividade de mariscagem, conforme relatado pelas marisqueiras.

Os resultados revelaram que a extração dos mariscos ocorre sem o uso de EPIs, restringindo ao uso de chapéu, camisa com manga comprida e calçados, mesmo assim, afirmaram que já se acidentaram com corte causado pelo peixe "Niquim", também conhecido como "peixe pedra" (Thalassophryne sp.). Freitas, et al. (2012), analisando o conhecimento tradicional das marisqueiras em Barra Grande, constataram que 61,9\% das entrevistadas afirmaram que para se proteger contra o sol, utilizam apenas camisa de manga comprida e boné, ao passo que $38,1 \%$ não utilizam nada como forma de proteção contra a radiação solar, que pode culminar em doenças graves na pele. Na região de estudo, a mariscagem é feita com 
o revolvimento do sedimento com as mãos e baldes, na qual os moluscos são extraídos e acondicionados em baldes. As marisqueiras ficam curvadas ou sentadas nas croas, sendo expostas a quatro ou cinco horas de sol por dia, de acordo com a duração da maré. Além dos riscos com acidentes, a segurança pode ficar comprometida, devido a insalubridade do trabalho (Cidreira-Neto et al., 2019).

Moura et al. (2008), destacam que a subvalorizarão do serviço das marisqueiras e o ambiente insalubre de trabalho, úmido e com presença de insetos, geram condições de trabalho inadequadas. Essa carga de trabalho, associadas à postura curvada durante a realização da coleta, além do peso dos baldes geram esse desconforto, propiciando um cenário favorável a uma atividade insalubre e sem segurança. De fato, levantamento feitos pelo Serviço de Saúde Ocupacional dos Hospital Universitário da Universidade Federal da Bahia, revelaram que em relação às enfermidades diagnosticadas em marisqueiras, as Lesões por Esforço Repetitivo (LER) e Distúrbios Osteomusculares Relacionados ao Trabalho (DORT) de membros superiores, de coluna e de joelho foram responsáveis por $67 \%$ dos casos, dos quais, 31,7\% apresentaram tendinopatia e bursite de ombro e 24,2\% Síndrome do Túnel do Carpo. Pena et al (2014b), constaram que durante a extração dos mariscos, há uma frequência média de 10.200 movimentos repetitivos por hora, enquanto, a título de comparação, para a atividade de digitador, a norma oficial estabelece o limite de 8.000 toques por hora, concluindo que marisqueiras deveriam ser incluídas dentre as profissões de riscos ocupacionais para LER, pois realizam atividades em ritmo acelerado, visando por sua sobrevivência e de sua família.

Em relação ao nível de escolaridade, as marisqueiras associadas possuem como maior grau, o nível médio, enquanto que entre as marisqueiras não-associadas apenas 12,4\% possuem o nível médio. Machado et al. (2010), em estudos sobre o perfil socioeconômico dos pescadores de ostra de mangue Crassostrea ssp. em Cananéia/São Paulo, destacaram que $14,5 \%$ dos entrevistados cursaram até o ensino médio, mas a maioria $(65 \%)$ só cursou até a $4^{\mathrm{a}}$ série do ensino fundamental, caracterizando a baixa escolaridade dos extrativistas. No estudo de Monteles et al. (2009), 60\% das marisqueiras não tinham completado o ensino fundamental, sendo que a metade era analfabeta. A baixa escolaridade pode ser ocasionada 
por outros motivos (familiares, ter filhos muito jovens, escolas não muito boas), sendo que as mulheres muitas vezes vão para a pesca do marisco por falta de outras oportunidades. Como vivem em condições econômicas precárias, as marisqueiras precisam realizar outras atividades para incrementarem suas rendas. Geralmente, são vinculadas à programas sociais, aposentadoria ou ainda possuem criação de animal para consumo próprio e venda. Entretanto, as pescadoras não-associadas não possuem aposentadoria. Muitas apresentam idade para se aposentar, no entanto, não possuem nenhum documento que comprovem que são pescadoras.

\section{CONSIDERAÇÕES FINAIS}

Podemos concluir que para a maioria das marisqueiras a pesca do marisco complementa os ganhos com aposentadorias e bolsa família, permitindo o custeio familiar somado a renda de seus cônjuges. A despeito dos problemas relacionados a atividade, as marisqueiras consideram que vale a pena continuar com a atividade da pesca do marisco $A$. brasiliana, indicando assim a importância da atividade mariscagem como fonte de renda e subsistência para estas pessoas. A organização das marisqueiras em associações, também é outro aspecto relevante que pode auxiliar a melhorar suas condições socioeconômicas. De acordo com as diretrizes da FAO (2015), para garantir s sustentabilidade da pesca em pequena escala, a mesma não pode ser analisada isoladamente, pois está inserida num contexto institucional e político mais amplo. Nesse contexto, é essencial ter informações sobre o conhecimento tradicional disponível nas comunidades pesqueiras e também entender qual situação econômica, social e ambiental a que estes pescadores estão submetidos, visando otimizar a colaborações em vários níveis entre as comunidades pesqueiras, pesquisadores e tomadores de decisão no intuito de garantir a elaboração de políticas públicas que possam ir ao encontro dos anseios desta população.

\section{AGRADECIMENTOS}

Agradecemos a Associação da Mulheres Pescadoras e Artesãs do Município de Grossos e a todas as mulheres da comunidade de marisqueiras das praias de Barra e Pernambuquinho pelo auxílio incondicional para a realização desta pesquisa. Agradecemos 
ainda os apoios financeiros da Coordenação de Aperfeiçoamento de Pessoal de Nível Superior (CAPES) do Conselho Nacional de Desenvolvimento Científico e Tecnológico (CNPq) e da ONG World Fisheries Trust do Canadá, por meio do Projeto Gente da Maré.

\section{REFERÊNCIAS}

ANDRADE, J.C.P.; SCHIAVETTI, A. Artisanal fishing and local conflicts: the case of the Pedras de Una? fishing community, Bahia, Brazil. Revista da Gestão Costeira Integrada, v. 15, n. 3, p. 425-438. 2015.

ARAÚJO, M.L.R. AND OCHA-BARREIRA, C.A., Distribuição Espacial de Anomalocardia brasiliana (Gmelin, 1791) (Mollusca, Bivalvia, Veneridae) na Praia do Canto da Barra, Fortim, Ceará, Brasil. Boletim Técnico Científico CEPENE, v.12, p. 11-21. 2004.

BEGOSSI, A. Temporal Stability in fishing spots: conservation and co-management in Brazilian Artesanal Coastal Fisheries. Ecology and Society, v. 11.1 - 5. 2006.

BEGOSSI, A.; HANAZAKI, N.; PERONI, N.; SILVANO, R.A.M.. Estudos de ecologia humana e etnobiologia: uma revisão sobre usos e conservação. In: C.F.D ROCHA; H. G. BERGALLO, M. A. S.; ALVES M. VAN SLUYS. (Ed.). Biologia da Conservação: Essências. p. 320-331, 2006.

BEGOSSI, A.; LOPES, P.F.; OLIVEIRA, L.E.C.; Nakano, H. 2009. Ecologia de Pescadores artesanais da Baía da Ilha Grande. Apoio CAPESCA: Preac/CIS-Guanabara/Lepac/CMU (Unicamp) \& IDRC, Canadá, 259 p.

BOEHS, G.; ABSHER, T.M.; CRUZ-KALED, A.C. Ecologia populacional de Anomalocardia brasiliana (GMELIN, 1791) (Bivalvia, Veneridae) na baía de Paranaguá, Paraná, Brasil. Boletim do Instituto de Pesca, v. 34, p. 259-270, 2008.

CHIBA, W.A.C.; ASSUNÇÃO, A.W.A.; TAKAO, L.K.; ROCHA, G.S.; JANKE, H.; VALSKO, J.; EBERT, L.A.; FIGUEROA, M.E.; CUNHA, S. Caracterização da produção pesqueira ao longo do tempo, no município de Cananéia, litoral Sul de São Paulo, Boletim do Instituto de Pesca, v. 38, p. 265 - 273, 2012.

CIDREIRA NETO, I. R. G.; FRAGOSO, M. L. B.; RODRIGUES, G. G.. PESCA. Artesanal do marisco no litoral paraibano: relações socioambientais e tecnologias sociais. Revista de Geografia (Recife), v. 36, p. 97-109, 2019.

DIAS, T.L.P.; ROSA, R.S.; DAMASCENO, L.C.P. Aspectos socioeconômicos, percepção ambiental e perspectivas das mulheres marisqueiras da reserva de desenvolvimento 
sustentável Ponta do Tubarão (Rio Grande do Norte, Brasil). Gaia Scientia, v. 1, p. 25-35. 2007.

FAO (Fisheries and Aquaculture Department). Rome, 2014. Disponível em: http://www.fao.org/faoterm/en/?defaultCollId=21. Acesso em: 09/janeiro/2020.

FAO (Fisheries and Aquaculture Department). 2015 Voluntary Guidelines for Securing Sustainable Small-Scale Fisheries. Rome, 2015. Disponível em: www.fao.org/3/a-i4487e.pdf acesso em 20/janeiro/2020.

FAO (Fisheries and Aquaculture Department). 2018. The State of World Fisheries and Aquaculture (SOFIA). Rome: Fisheries and Aquaculture Department, p. 253.

FREITAS, S.T.; PAMPLI, P.A.Z.; LEGAT, J.; FOGAÇA, F.H.S.; BARROS, R.F.M. Conhecimento tradicional das marisqueiras de Barra Grande, área de proteção ambiental do Delta do Rio Paraíba, Piauí, Brasil. Ambiente e Sociedade. v. 15, p. 91-112, 2012.

GELCICH, S.; MARTINEZ-HARMS, M.; TAPIA-LEWIN, S.; LAVÍN, F.; RUANOCHAMORRO, C. Comanagement of small-scale fisheries and ecosystem services. Conservation Letters: e12637, 2019.

GOMES, J.O.L.; MELO, A.S.; LOPES, S.F.; MOURAO, J.S. Techniques for Catching the Shellfish Anomalocardia flexuosa in a Tropical Estuary in Northeast Brazil. Human Ecology, p. 1-17, 2019.

GUEST, G. Fishing behavior and decision-making in an Ecuadorian community: a scaled approach. Human Ecology, v.31, p.611-644, 2003.

HENRY-SILVA, G.G.; CAROLSFELD, J; GALVEZ, A.O. 2014a. Gente da maré: aspectos ecológicos e socioeconômicos de mariscagem do nordeste brasileiro. 1. ed. Mossoró:

EDUFERSA, v. 1.418 p.

HENRY-SILVA, G.G.; COSTA, R.S.; BELEM, T.P.; RODRIGUES, A.M.L.; MOURA, R. S.T. 2014b. Ecologia populacional e manejo pesqueiro de Anomalocardia brasiliana. In: Gustavo Gonzaga Henry-Silva; Joachim Carolsfeld; Alfredo Olivera Gálvez. (Org.). Gente da maré: aspectos ecológicos e socioeconômicos de mariscagem do nordeste brasileiro. 1ed.Mossoró: Edufersa, v. 1, p. 117-156.

HENRY-SILVA, G.G.; MARTINS, I.X.; RABELO, E.F.; SILVA, E. J. 2017. Guia Ilustrado de Moluscos do Litoral Oeste Potiguar. 1. ed. Mossoró: Edufersa, 2017. v. 1. 130 p.

HENS, L. and BEGOSSI, A. 2008. Diversity and management: from extractive to farming systems. Environment Development and Sustainability, 10: 559-563. 
MACHADO, I.C.; FAGUNDES, L.; HENRIQUES, M.B. 2010. Perfil socioeconômico da ostra de Mangue Crassostrea ssp. em Cananéia, São Paulo, Brasil. Informações Econômicas, 40(7): 67-79.

MACNAUGHTON, A.E..; CAROLSFELD, J.; HENRY-SILVA, G.G. Diretrizes Estratégicas: Continuidade e Fortalecimentos das Ações e Resultados do Projeto Gente da Maré In: Gustavo Gonzaga Henry-Silva; Joachim Carolsfeld; Alfredo Olivera Gálvez. (Org.). Gente da maré: aspectos ecológicos e socioeconômicos de mariscagem do nordeste brasileiro. 1ed. Mossoró: Edufersa, v. 1, p. 385-403.

MATTOS, S; WOJCIECHOWSKI, M.J.; MACNAUGHTON, A.E.; HENRY-SILVA, G.G.; RODRIGUES, A.M.L.; CAROLSFELD, J. Implementing the Small-Scale Fisheries Guidelines: Lessons from Brazilian Clam Fisheries. In: Svein Jentoft; Ratana Chuenpagdee; Maria José Barragán-Paladines; Nicole Franz. (Org.). MARE Publication Series. 14ed.: Springer International Publishing, 2017, p. 473-494.

MEDEIROS, M.C., BARBOZA, R.R.D; MARTEL, G.; MOURÃO, J.S. Combining local fishers' and scientific ecological knowledge: implications for co-management. Ocean and Coastal Management, v.158, p. 1-10, 2018.

MONTELES, J.S.; CASTRO, T.C.S.; VIANA, D.C.O.; CONCEIÇÃO, F.S.; FRANÇA, V.L.; FUNO, I.C.S. 2009. Percepção socioambiental das marisqueiras no município de Raposa, Maranhão, Brasil. Revista Brasileira de Engenharia de Pesca, v.4, p. 34-45, 2009.

MOURA, D.F.G.; SANTOS NETO, A.O.; ALMEIDA, R.O. A etnoecologia das marisqueiras da comunidade de Praia Grande, Ilha de Maré, Salvador-BA. Candombá, Revista Virtual, v.4, p. 91-110. 2008.

MOURÃO, JS; BARACHO, R.L.; MARTEL, G.; BARBOZA, R.R,D; LOPES, S.F. Local ecological knowledge of shellfish collectors in an extractivist reserve, Northeast Brazil: implications for co-management. Hydrobiologia, v. 3, p. 2-25. 2020.

NISHIDA, A.K.; NORDI N.; ALVES, R.R.N. Abordagem Etnoecológica da Coleta de Moluscos no Litoral Paraibano. Tropical Oceanography. 32:53-68. 2004.

NISHIDA, A.K.; NORDI, N.; ALVES, R.R.N. Mollusk Gathering in Northeast Brazil: An Ethnoecological Approach. Human Ecology, v. 34, p.133-145, 2006.

NISHIDA, A.K.; NORDI, N.; ALVES, R.R.N. Aspectos Socioeconômicos dos Catadores de Moluscos do Litoral Paraibano, Nordeste do Brasil. Revista de Biologia e Ciências da Terra, v. 8, p. 207-215, 2008. 
NOTTINGHAM, C.D.; WHITE, W.L. Annual Reproductive Cycle and Condition Index of the New Zealand Surf Clam Mactra murchisoni (Deshayes, 1854) (Bivalvia: Mactridae), Journal of Shellfish Research, v.34, n. 3, p.777-784. 2015.

OLIVEIRA, I.B.; SILVA NETO, S.R.; LIMA FILHO, J.V.M.; PEIXOTO, S.R.M.; GALVEZ, A. O. Efeito do período chuvoso na extração do molusco bivalve Anomalocardia brasiliana (Gmelin, 1791). Revista Brasileira Ciências Agrárias, v.9, n. 1, p. 139-145, 2014.

PENA, P.G.L.; MARTINS, V.L.A.; FREITAS, M.C.; GOMES, T.M.D; SEIXAR, J.; MARTINS, Y.D.; PINHO, M.C. Trabalho acelerado nas marés e riscos ocupacionais para pescadoras marisqueiras. In: Gustavo Gonzaga Henry-Silva; Joachim Carolsfeld; Alfredo Olivera Gálvez. (Org.). Gente da maré: aspectos ecológicos e socioeconômicos de mariscagem do nordeste brasileiro. 1ed.Mossoró: Edufersa, v. 1, p. 203-248. 2014a.

PENA, P.G.L.; MARTINS, V.L.A.; FREITAS, M.C.; GOMES, T.M.D; SEIXAR, J.; MARTINS, Y.D.; PINHO, M.C. Lesões por esforços repetitivos em pescadoras marisqueiras. In: Gustavo Gonzaga Henry-Silva; Joachim Carolsfeld; Alfredo Olivera Gálvez. (Org.). Gente da maré: aspectos ecológicos e socioeconômicos de mariscagem do nordeste brasileiro. 1ed.Mossoró: Edufersa, v. 1, p. 249-272. 2014b.

PEZZUTO, P.R., ECHTERNACHT, A.M. 1999. Avaliação de impactos da construção da Via Expressa SC-Sul sobre o berbigão Anomalocardia brasiliana (Gmelin, 1791) (Mollusca: Pelecypoda) na Reserva Extrativista Marinha do Pirajubaé (Florianópolis, SC - Brasil). Atlântica, 21: 105-119.

RIOS, E.C. 2009. Seashells of Brazil. 3. ed. Rio Grande: Editora da Fundação Universidade do Rio Grande, 331 p.

ROCHA, L. M. 2013. Ecologia humana e manejo participativo da pesca do marisco Anomalocardia brasiliana (Gmelin,1791) (bivalvia: veneridae) na Reserva de Desenvolvimento Sustentável Estadual Ponta do Tubarão (RN). Tese de Doutorado. UFRN, RN.

ROCHA, L.M.; PINKERTON, E.. Comanagement of clams in Brazil: a framework to advance comparison. Ecology and Society: a journal of integrative science for resilience and sustainability, v. 20.

ROCHA-BARREIRA, C.A.; ARAÚJO, M.L.R. Ciclo Reprodutivo de Anomalocardia brasiliana (Gmelin, 1791) (Mollusca, Bivalvia, Veneridae) na praia do Canto da Barra, Fortim, Ceará, Brasil. Boletim do Instituto de Pesca, v.31, p. 9-20, 2005.

RODRIGUES, A.M.L.; AZEVEDO, C.M.S.B.; COSTA, R.S.; HENRY-SILVA, G.G. 
Population structure of bivalve Anomalocardia brasiliana (Gmelin, 1791) in semi-arid estuarine region of Northeast Brazil. Brazilian Journal of Biology, v.73, n. 5, p. 819-833. 2013.

SANTOS, A.P.S.; Camargo M.; ESTUPINAN, R.A.; GOES, V.C.; MEDEIROS, J.M. 2017. Alternativas de aproveitamento das conchas de marisco de Anomalocardia flexuosa (Linnaeus, 1767) como material agregado para a elaboração de tijolos ecológicos na comunidade de marisqueiras do Renascer, Cabedelo, Paraíba. Gaia Scientia, v. 11, p. 77, 2017.

SOUTO, F.B.; MARTINS, V.S. Conhecimentos Etnoecológicos na Mariscagem de Moluscos Bivalves no Manguezal do Distrito de Acupe, Santo Amaro - BA. Biotemas, v. 22: p. 207$218,2009$. 